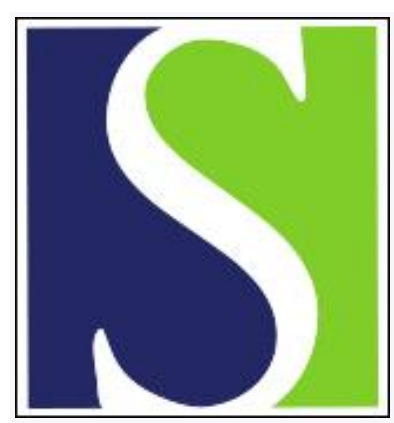

Scand J Work Environ Health 1985;11(2):75-82

https://doi.org/10.5271/sjweh.2242

Issue date: Apr 1985

Cancer risk of arc welders exposed to fumes containing chromium and nickel.

by Becker N, Claude J, Frentzel-Beyme R

This article in PubMed: www.ncbi.nlm.nih.gov/pubmed/4001902

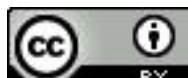




\title{
Cancer risk of arc welders exposed to fumes containing chromium and nickel
}

\author{
by Nikolaus Becker, DrScHum, Jenny Claude, MHS, Rainer Frentzel-Beyme, MD, MHS ${ }^{1}$
}

\begin{abstract}
BECKER N, CLAUDE J, FRENTZEL-BEYME R. Cancer risk of arc welders exposed to fumes containing chromium and nickel. Scand J Work Environ Health 11 (1985) 75-82. A retrospective follow-up study among chromium- and nickel-exposed welders, which took into consideration welding procedures, duration of exposure, and smoking habits, yielded an increased cancer risk in a comparison with an internal reference group of turners, milling cutters, and drillers, as well as in a comparison with the general population of the Federal Republic of Germany. Due to the cohort size (1 224 welders, 1694 turners) and the fact that the observation period is still too short, confirmed statements as to the target cancer sites cannot yet be made. However, it emerges that welding with coated electrodes shows a higher cancer risk as compared to the other welding processes observed. This finding may be explained by the fact that the share of hexavalent chromium compounds in the welding fumes is greater with coated electrodes than with other processes so that a follow-up study observing the health risks of chromium and nickel fumes separately would be warranted. For the confirmation of a more favorable outcome with gas-shielded welding, a larger investigation group or a longer observation period would be required.
\end{abstract}

Key terms: epidemiology, follow-up, internal reference, mortality, turners.

Ever since the 1930s the carcinogenic effect of nickel (occurring in the form of respirable dusts or aerosols, as well as sulfide, oxide and carbonyl) on man has been known as one of its essential toxic properties $(11,12,15)$. In numerous studies it was shown that dusts developing during the refinement of the metal may, upon inhalation, lead to the development of malignant tumors in the lung and the sinonasal region $(5,6,7,11,13,22)$. In the same way, carcinomas of the lung have been produced by the inhalation of nickel compounds in experimental studies with rodents, and sarcomas and carcinomas of other sites have been caused by the intravenous injection of nickel carbonyl. Although the mean latency period of tumor development in workers in refineries ranges between 13 and 30 years, some cases have already been observed after less than 5 years, while others have occurred more than 50 years after the beginning of the exposure. Apart from nickel smelting, nickel dusts may occur anywhere in the ambient air where nickel is being processed as an additive, eg, when chromium-nickel steels are welded, even if at a considerably lower concentration.

Some compounds of hexavalent chromium are also known for their human carcinogenic potential. In this case, too, the increased incidence of lung carcinoma is predominant, although tumors of other sites (eg, of the paranasal sinus) are also found more fre-

1 Institute of Documentation, Information and Statistics, German Cancer Research Center, Heidelberg, Federal Republic of Germany.

Reprint requests to: Dr N Becker; Institute of Documentation, Infornuation and Statistics; German Cancer Research Center; Heidelberg; FRG. quently than expected. So far, these malignancies have been preponderantly ascribed to the influence of chromate-containing dust from the oxidation process following chromate alkaline production (a process which is no longer in use) but also following exposure to zinc chromate pigment (14).

The use of chromium-nickel alloy electrodes in arc welding may lead to exposure to both metals through the inhalation of welding fumes, the composition of which depends on the type of electrode and the respective amounts of chromium and nickel. On account of the chemical and physical properties of the electrodes the amount of chromium and nickel in the fumes may vary, but it will always be considerably less than their portion in the electrode itself. The properties of the welded steels (parent metal), however, may be left out of consideration.

About $70 \%$ of all welding work in the austenitic field is covered by two techniques, (i) arc welding with coated chromium-nickel alloyed rod electrodes and (ii) gas-shielded welding with uncoated chromiumnickel alloyed wire electrodes, the welding point being shielded by a continuous stream of an inert gas against access to air.

Arc welders who use such electrodes are mostly subjected to a mixed exposure of chromium and nickel. The fume generated during arc welding with coated electrodes contains a markedly larger amount of hexavalent chromium compounds than that from gas-shielded welding. Furthermore, alkaline-coated rod electrodes appear to release considerably more chromium than other electrodes. The concentration of hexavalent chromium in the welding fumes is also higher than that of nickel (28). 
Medical investigations of arc welders in Germany have shown that a mixed exposure to chromium and - to a less extent - nickel can be shown from measurements of the excretion of both metals $(28,29)$. Such cross-sectional studies assessing the external and internal strain on the respiratory tract of arc welders working with chromium-nickel alloyed filler metal, however, cannot be used to estimate cancer risk. Therefore the Metal Division of the Mutual Accident Insurance Association approached the Department of Epidemiology of the German Cancer Research Center in 1979 with a request to carry out an epidemiologic investigation of the cancer risk of arc welders. The main objective was to identify and to quantify the carcinogenic effects of nickel compounds in the welding fumes. In the course of the data acquisition, it turned out that the number of arc welders working exclusively with nickel-containing electrodes was too small for an epidemiologic study. Arc welders possibly subjected to a mixed exposure in the above sense, ie, all chromium-nickel welders, were thus included in the study in order to answer the basic question of whether any health risk can be established at all.

\section{Materials and methods}

A historical follow-up study was feasible since the welding of stainless steel in the Federal Republic of Germany was introduced at the beginning of the 1950 s. However, only very few such exposed welders could be anticipated in the individual factories in this early period. In order that a justifiable cohort size (aimed at 1500 ) could be obtained, a total of 25 factories distributed throughout the Federal Republic had to be included in the study. They are manufacturers of sanitary installations, power plants, and boilers.

The study cohort was to include persons first exposed before 1970. In order to account for a latency period of at least 10 years, cancer cases to be related to the exposure in question could not be expected among persons employed at a later date.

The complete coverage of the persons employed at the time was facilitated by the fact that regulations in the manufacture of pressure vessels used in boilers, power plants, and installation construction require that those workers to be entrusted with high-alloy steel welding undergo an official technical examination (TÜV) at intervals of two years. Thus, it was possible to set up complete lists of all the chromiumnickel welders ever employed through the use of the certificates available in most of the factories from the very beginning.

In order to narrow down the nickel exposure in the evaluation, an internal reference group was defined, which was to be similar to the group of welders with regard to the basic characteristics (type of industry, physical stress, etc) but definitely not exposed to nickel and chromium. The work area of mechanical processing (turning, milling, drilling) was chosen, where the waste product only consists of particles which are not airborne and inhaled. It should be noted, however, that this occupational group was exposed to mineral cutting oils, which, due to the fact that they contain nitrosamines, may possibly represent a cancer risk. The data on the reference group ("turners") was also collected in most of the 25 factories. To ensure statistically robust results, a cohort size of 3000 was aimed at, which means that a reference cohort about twice the size of that of the welders was to be set up in each factory. Since mechanical processing requires no certificates, the turners' names had to be taken from wage lists, departmental books, etc. Analogous to the study group all turners ever employed since 1950 were then established with the aid of personnel files.

For the two cohorts, home address, date of entering and leaving the firm, and date of beginning and end of exposure were collected from personnel records. Data on smoking habits were collected in interviews with the foremen. For the group of welders, additional technical details concerning the electrodes used, the welding processes, the conditions under which welding took place (eg, in the vessel or on assembly), and the proportion of welding in the entire worktime were ascertained. The acquisition of data, therefore, took place exclusively through the review of documents and interviews of superiors or employees in the personnel departments without direct contact with the persons concerned.

Table 1. Results of the follow-up of welders and turners.

\begin{tabular}{|c|c|c|c|c|c|c|}
\hline & \multicolumn{2}{|c|}{ Welders } & \multicolumn{2}{|c|}{ Turners } & \multicolumn{2}{|c|}{ Total } \\
\hline & Number & $\%$ & Number & $\%$ & Number & $\%$ \\
\hline \multicolumn{7}{|l|}{ Number of persons } \\
\hline $\begin{array}{l}\text { Alive } \\
\text { Dead } \\
\text { Lost to follow-up }\end{array}$ & $\begin{array}{r}1119 \\
77 \\
25\end{array}$ & $\begin{array}{r}91.6 \\
6.3 \\
2.1\end{array}$ & $\begin{array}{r}1491 \\
163 \\
40\end{array}$ & $\begin{array}{r}88.0 \\
9.6 \\
2.4\end{array}$ & $\begin{array}{r}2610 \\
240 \\
65\end{array}$ & $\begin{array}{r}89.5 \\
8.2 \\
2.3\end{array}$ \\
\hline Total & 1221 & 100 & 1694 & 100 & 2915 & 100 \\
\hline \multicolumn{7}{|l|}{ Death certificates } \\
\hline $\begin{array}{l}\text { Available } \\
\text { Not available }\end{array}$ & $\begin{array}{r}76 \\
1\end{array}$ & . & $\begin{array}{r}155 \\
8\end{array}$ & $\dot{.}$ & $\begin{array}{r}231 \\
9\end{array}$ & . \\
\hline Person-years at risk & 23492 & . & 41243 & . & 64735 & . \\
\hline
\end{tabular}


The data acquisition, which commenced in August 1980 and terminated in March 1982, yielded cohorts of 1221 welders and 1694 turners, and therefore the anticipated figures could not be reached.

The follow-up was complicated by restrictions due to the regulations of data protection and lasted until 15 January 1983. In spite of all difficulties, the follow-up was complete for $96 \%$ of the subjects.

The evaluation of the data was carried out with the use of the computer package EPAS (3) for the analysis of epidemiologic studies prepared at the German Cancer Research Center and written in APL precisely according to the methods presented by Rothman \& Boice (25). The person-years at risk of dying since first exposure were computed, and Miettinen's rate ratio estimate and test-based $95 \%$ confidence intervals were used to calculate the relative risks of death in a comparison of the two cohorts (internal comparison). Control of smoking as a confounder and analysis by duration of exposure were performed. In addition the two groups were compared with the total population mortality (external comparison). Quinquennial age-calendar time and cause-specific mortality rates of the Federal Republic of Germany for males from 1952 to 1978 were used in the calculation of the expected values and standardized mortality ratios (SMR). On the assumption of the Poisson distribution, approximate $95 \%$ confidence limits were computed.

\section{Results}

The results of the follow-up are shown in table 1. Only $2.3 \%$ of the subjects were lost to follow-up. There were 77 deaths in the welders' and 163 in the turners' cohort. Death certificates were available for $96.3 \%$ of the deaths. The age distribution of the two cohorts is shown in table 2. As was to be expected from the general mortality statistics, the most frequent causes of death in both groups were the diseases of the cardiovascular system, with 27 and 75 cases, respectively, as well as deaths from malignant neoplasms (23 and 30 cases) (table 3 ). With the exception of violent deaths, other causes of death ranged below 12 cases each. When the deaths from malignant neoplasms were differentiated according to site, cancers of the respiratory organs, with 6 and 10 cases, respectively, ranked first followed by 2 and 5 cases of stomach cancer (table 4). For most other sites the figures were 5 and below.

\section{Internal comparison}

For a consideration of the confounding factor smoking, a stratification by smokers, nonsmokers, and former smokers was done. The results of this evaluation compared to a simple evaluation showed no significant differences in the rate ratios, so that smoking was not considered in the further analyses.

Table 2. Age distribution of the cohorts at entry into the study.

\begin{tabular}{lccccc}
\hline \multirow{2}{*}{$\begin{array}{l}\text { Age group } \\
\text { (years) }\end{array}$} & \multicolumn{2}{c}{ Welders } & & \multicolumn{2}{c}{ Turners } \\
\cline { 2 - 3 } \cline { 5 - 6 } & Number & $\%$ & & Number & $\%$ \\
\hline $10-14$ & 79 & 6.5 & & 416 & 24.6 \\
$15-19$ & 175 & 14.3 & & 382 & 22.6 \\
$20-24$ & 247 & 20.2 & & 288 & 17.0 \\
$25-29$ & 301 & 24.7 & & 218 & 12.9 \\
$30-34$ & 192 & 15.7 & & 136 & 8.0 \\
$35-39$ & 122 & 10.0 & & 96 & 5.7 \\
$40-44$ & 62 & 5.1 & & 68 & 4.0 \\
$45-49$ & 28 & 2.3 & & 56 & 3.3 \\
$50-54$ & 8 & 0.7 & & 26 & 1.5 \\
$55-59$ & 6 & 0.5 & & 7 & 0.4 \\
$60-64$ & 1 & 0.1 & & 1 & 0.1 \\
\hline Total & 1221 & 100.0 & 1694 & 100.0 \\
\hline
\end{tabular}

Table 3. Cause-specific deaths among welders and turners and rate ratios for the total period of observation.

\begin{tabular}{|c|c|c|c|c|}
\hline \multirow{2}{*}{ Cause of deatha } & \multicolumn{2}{|c|}{ Number of deaths } & \multirow{2}{*}{$\begin{array}{l}\text { Rate } \\
\text { ratio }\end{array}$} & \multirow{2}{*}{$\begin{array}{c}\text { Confidence } \\
\text { limits }\end{array}$} \\
\hline & Welders & Turners & & \\
\hline All causes $(000-999)$ & 77 & 163 & 1.1 & $0.8-1.3$ \\
\hline Infectious diseases $(000-136)$ & 2 & 2 & 1.5 & $0.7-3.1$ \\
\hline Malignant neoplasms $(140-209)$ & 23 & 30 & $2.4^{*}$ & $1.1-5.1$ \\
\hline Neoplasms of unspecified nature $(230-239)$ & - & 1 & $\cdot$ & $\cdot$ \\
\hline Endocrine, metabolic and immunity disorders (240-279) & - & 1 & . & . \\
\hline Blood and blood-forming organs $(280-289)$ & - & 1 & . & . \\
\hline Mental disorders $(290-315)$ & - & 1 & $\cdot$ & $\cdot$ \\
\hline Circulatory system (390-458) & 27 & 75 & 0.5 & $0.1-4.5$ \\
\hline Respiratory system $(460-519)$ & 2 & 6 & 0.6 & $0.0-18.3$ \\
\hline Digestive system $(520-577)$ & 5 & 12 & 1.5 & $\cdot$ \\
\hline Genitourinary system $(580-607)$ & 2 & 4 & 1.5 & $0.2-12.5$ \\
\hline Symptoms, signs and ill-defined conditions (780-796) & 3 & 10 & 6.1 & . \\
\hline Accidents, poisonings, violence $(800-999)$ & 13 & 20 & 2.5 & . \\
\hline
\end{tabular}

* $p<0.05$

a As classified in the eighth revision of the International Classification of Diseases.

b Adjusted by stratification for age. 
Table 4. Site-specific cancer deaths among welders and turners and rate ratios for the total period of observation.

\begin{tabular}{|c|c|c|c|c|}
\hline \multirow{2}{*}{ Cause of death ${ }^{a}$} & \multicolumn{2}{|c|}{ Number of deaths } & \multirow{2}{*}{$\begin{array}{l}\text { Rate } \\
\text { ratiob }\end{array}$} & \multirow{2}{*}{$\begin{array}{l}\text { Confidence } \\
\text { limits }\end{array}$} \\
\hline & Welders & Turners & & \\
\hline Malignant neoplasms $(140-209)$ & 23 & 30 & $2.4^{*}$ & $1.1-5.1$ \\
\hline Gastrointestinal tract $(150-159)$ & 6 & 8 & 1.4 & $0.8-2.4$ \\
\hline $\begin{array}{l}\text { Esophagus (150) } \\
\text { Stomach (151) }\end{array}$ & $\begin{array}{l}1 \\
2\end{array}$ & $\overline{5}$ & 1.4 & $0.2-12.5$ \\
\hline Intestine (152-154) & 1 & - & 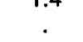 & $\begin{array}{c}0.2-12.3 \\
.\end{array}$ \\
\hline Liver (155) & - & 1 & i. & : \\
\hline Gall bladder (156) & - & 1 & . & \\
\hline Pancreas (157) & 2 & 1 & 3.7 & $0.6-24.5$ \\
\hline Peritoneum (158) & 1 & - & . & . \\
\hline Trachea, bronchus, lung (162) & 6 & 10 & 1.7 & $0.7-4.0$ \\
\hline Other respiratory organs (163) & 2 & - & . & . \\
\hline Melanoma (172) & 1 & 1 & 3.7 & $0.2-65.8$ \\
\hline Prostate (185) & 1 & 1 & 4.0 & $0.3-50.2$ \\
\hline Urinary organs $(188-189)$ & 3 & 2 & 15.0 & . \\
\hline Brain (191) & 2 & 1 & 3.8 & $0.5-31.2$ \\
\hline Secondary neoplasms (197) & 1 & 1 & 3.7 & $0.3-54.2$ \\
\hline Unspecified sites (199) & - & 1 & . & . \\
\hline Leukemia and lymphatic system (200-209) & - & 5 & . & . \\
\hline Neoplasms of unspecified nature of respiratory organs (231) & - & 1 & . & . \\
\hline
\end{tabular}

* $p<0.05$

a As classified by the eighth revision of the International Classification of Diseases.

b Adjusted by stratification for age.

Table 5. Mortality analysis for welders and turners for the total period of observation.

\begin{tabular}{|c|c|c|c|c|c|c|}
\hline \multirow{3}{*}{ Cause of deatha } & \multicolumn{3}{|c|}{ Welders } & \multicolumn{3}{|c|}{ Turners } \\
\hline & \multicolumn{2}{|c|}{ Deaths } & \multirow{2}{*}{$\begin{array}{l}\text { Standardized } \\
\text { mortality ratio }\end{array}$} & \multicolumn{2}{|c|}{ Deaths } & \multirow{2}{*}{$\begin{array}{l}\text { Standardized } \\
\text { mortality ratio }\end{array}$} \\
\hline & Observed & Expected & & Observed & Expected & \\
\hline All causes $(000-999)$ & 77 & 117.4 & $65.6^{\star}$ & 163 & 254.3 & $641^{*}$ \\
\hline Infectious diseases $(000-136)$ & 2 & 4.1 & 47.9 & 2 & 6.2 & 32.2 \\
\hline $\begin{array}{l}\text { Malignant neoplasms }(140-209) \\
\text { Gastrointestinal tract }(150-159) \\
\text { Stomach (151) } \\
\text { Trachea, bronchus, lung (162) } \\
\text { Melanoma (172) } \\
\text { Prostate }(185) \\
\text { Leukemia (204-207) }\end{array}$ & $\begin{array}{r}23 \\
6 \\
2 \\
6 \\
1 \\
1 \\
-\end{array}$ & $\begin{array}{r}23.7 \\
6.5 \\
3.4 \\
6.3 \\
0.3 \\
0.9 \\
1.2\end{array}$ & $\begin{array}{r}97.1 \\
92.3 \\
58.3 \\
95.4 \\
318.4 \\
115.1 \\
\end{array}$ & $\begin{array}{r}30 \\
8 \\
5 \\
10 \\
1 \\
1 \\
5\end{array}$ & $\begin{array}{r}53.1 \\
15.3 \\
8.3 \\
14.5 \\
0.5 \\
2.6 \\
2.3\end{array}$ & $\begin{array}{r}56.5 \\
52.2 \\
59.5 \\
69.2 \\
203.6 \\
38.5 \\
214.8\end{array}$ \\
\hline $\begin{array}{l}\text { Neoplasms of unspecified } \\
\text { nature }(230-239)\end{array}$ & - & 1.3 & . & 1 & 2.6 & 38.0 \\
\hline Circulatory system (390-458) & 27 & 35.7 & 75.6 & 75 & 82.7 & 90.7 \\
\hline Respiratory system (460-519) & 2 & 5.7 & 34.8 & 6 & 14.9 & 40.3 \\
\hline Digestive system $(520-577)$ & 5 & 10.7 & 46.8 & 12 & 20.4 & 58.8 \\
\hline Genitourinary system $(580-607)$ & 2 & 2.1 & 96.6 & 4 & 5.1 & 78.0 \\
\hline $\begin{array}{l}\text { Accidents, poisonings, violence } \\
(800-999)\end{array}$ & 13 & 23.7 & $54.9^{*}$ & 20 & 43.0 & $46.5^{*}$ \\
\hline
\end{tabular}

* $\mathrm{p}<0.05$.

a As classified by the eighth revision of the International Classification of Diseases.

The two groups were balanced with regard to the confounder smoking.

When age was adjusted for (using four age groups, $0-34,35-54,55-69$, and over 70 years), the rate ratio of malignant neoplasms for welders was statistically significant above 1.0 (table 3 ). A notable observation was the two cases of malignant neoplasms of "other respiratory organs" (mesotheliomas) among welders, although none was found among turners (table 4).

Analysis by duration of exposure did not show any striking differences between the groups.

\section{External Comparison}

The standard mortality ratios of both the welders and turners were predominantly below 100 (table 5). Al- 
Table 6. Mortality analysis by time since first exposure for welders and turners. (ICD = International Classification of Diseases)

\begin{tabular}{|c|c|c|c|c|c|c|}
\hline \multirow{3}{*}{$\begin{array}{l}\text { Time since first exposure } \\
\text { (years) }\end{array}$} & \multicolumn{3}{|c|}{ Welders } & \multicolumn{3}{|c|}{ Turners } \\
\hline & \multicolumn{2}{|c|}{ Deaths } & \multirow{2}{*}{$\begin{array}{l}\text { Standardized } \\
\text { mortality ratio }\end{array}$} & \multicolumn{2}{|c|}{ Deaths } & \multirow{2}{*}{$\begin{array}{l}\text { Standardized } \\
\text { mortality ratio }\end{array}$} \\
\hline & Observed & Expected & & Observed & Expected & \\
\hline
\end{tabular}

All causes (ICD 000-999)

$$
\begin{array}{r}
\leq 9 \\
10-19 \\
20-29 \\
\geq 30 \\
\text { Total }
\end{array}
$$

$\begin{array}{rr}10 & 32.3 \\ 24 & 42.3 \\ 32 & 34.7 \\ 11 & 8.1 \\ 77 & 117.4\end{array}$

$31.0^{\star}$
$56.7^{\star}$
92.2
135.9
$65.6^{\star}$

15
51
69
28
163

43.5
68.4
81.3
61.1

$34.5^{*}$

$74.6^{*}$

84.9

$45.8^{*}$

Malignant neoplasms (ICD 140-209)

$\leq 9$
$10 \div 19$
$20-29$
$\geq 30$

$\begin{array}{rr}1 & 4 . \\ 6 & 8.7 \\ 11 & 8.3 \\ 5 & 1.9 \\ 23 & 23.7\end{array}$

$\begin{array}{rr}4.8 & 20.8 \\ 8.7 & 69.3 \\ 8.3 & 132.7 \\ 1.9 & 258.1^{*} \\ 23.7 & 97.1\end{array}$

1
10
13
6
30

$\begin{array}{rl}6.2 & 16.2 \\ 13.8 & 72.7 \\ 18.8 & 69.2 \\ 14.4 & 41.8^{\star} \\ 53.1 & 56.5\end{array}$

Lung cancer (ICD 162)

$\leq 9$
$10 \leq 19$
$20-29$
$\geq 30$
Total

$\begin{array}{rrr}- & 1.0 & \\ 1 & 2.3 & 43.3 \\ 4 & 2.5 & 163.0 \\ 1 & 0.6 & 175.6 \\ 6 & 6.3 & 95.4\end{array}$

\begin{tabular}{|c|c|c|c|c|c|c|}
\hline \multirow{3}{*}{$\begin{array}{l}\text { Time since first exposure } \\
\text { (years) }\end{array}$} & \multicolumn{3}{|c|}{ Welders using coated electrodes } & \multicolumn{3}{|c|}{ Welders using other techniques } \\
\hline & \multicolumn{2}{|c|}{ Deaths } & \multirow{2}{*}{$\begin{array}{l}\text { Standardized } \\
\text { mortality ratio }\end{array}$} & \multicolumn{2}{|c|}{ Deaths } & \multirow{2}{*}{$\begin{array}{l}\text { Standardized } \\
\text { mortality ratio }\end{array}$} \\
\hline & Observed & Expected & & Observed & Expected & \\
\hline
\end{tabular}

$\begin{array}{rrrr} & & 1.3 & \\ 43.3 & 3 & 3.7 & 82.0 \\ 63.0 & 4 & 5.4 & 74.0 \\ 75.6 & 3 & 4.1 & 73.3 \\ 95.4 & 10 & 14.5 & 69.2\end{array}$

$* p<0.05$

Table 7. Mortality analysis by time since first exposure for the subgroups of welders using coated electrodes and welders using other techniques. (ICD = International Classification of Diseases)

All causes (ICD 000-999)

$$
\begin{array}{r}
\leq 9 \\
10-19 \\
20-29 \\
\geq 30
\end{array}
$$

Total

$\begin{array}{rr}8 & 22.8 \\ 21 & 32.6 \\ 30 & 28.6 \\ 9 & 7.2 \\ 68 & 91.2\end{array}$

Malignant neoplasms (ICD 140—209)

$$
\begin{gathered}
\leq 9 \\
10-19 \\
20-29 \\
\geq 30 \\
\text { Total }
\end{gathered}
$$

$\begin{array}{rr}1 & 3.5 \\ 5 & 6.8 \\ 10 & 6.9 \\ 4 & 1.7 \\ 20 & 19.0\end{array}$

Lung cancer (ICD 162)

$$
\begin{array}{r}
\leq 9 \\
10-19 \\
20-29 \\
\geq 30
\end{array}
$$

Total

* $p<0.05$.

though the corresponding ratio for a few specific cancer sites was above 100 , they should be ascribed to chance fluctuations due to the extremely small numbers.

Analysis by time since first exposure was performed for all causes of death, malignant neoplasms, and lung cancer (table 6). The results for welders clearly showed the healthy worker effect. In the first two time intervals the standardized mortality ratio was markedly below 100. It increased to above 100 with increasing observation time and reached statistical significance for malignant neoplasms in the last 
time interval of $\geq 30$ years since first exposure. Contrary to that of welders, the standardized mortality ratios of the turners showed no upward trend, many of them being significantly below 100 . Thus the mortality of the turners accentuates the extent of the health risk involved for the welders.

In view of the different composition of the welding fumes, the exposure of welders working mainly with coated electrodes and those engaged in other welding techniques were separately analyzed. For all of the different causes of death considered (as far as available data allowed), the standardized mortality ratios, though mostly still below 100 , were always higher for the welders using coated electrodes.

This finding was strengthened by the results from the analysis by time since first exposure (table 7). The standardized mortality ratios increased more rapidly with time for the welders using coated electrodes although the numbers were still too small to allow a reliable interpretation, since, for example, a single case of lung cancer in the group of other welders was responsible for the unusually high standardized mortality ratios in the last time interval for both malignant neoplasms and lung cancer.

One finding deserves attention although it is a chance finding in this study, namely, the five observed leukemia deaths among the turners (table 5). Compared with 2.3 expected deaths, a standardized mortality ratio of 215 was found; however it was not statistically significant. On the other hand, not a single case of leukemia was found among the welders. Information about turning procedures indicates that especially before 1960 cutting fluids with a mineral oil base were widely used, which also contained high proportions of aromatic hydrocarbons. Furthermore, benzene was in use as a cleaning fluid practically everywhere. Four of the five deceased entered their occupation before 1950 .

\section{Discussion}

According to Armstrong (1) epidemiologic investigations may help to detect and prevent new carcinogenic risks that have not even been established in animal experiments. In this respect it may be of interest that the history of the detection of carcinogenesis of metals began with the observation of malignant tumors in nickel refineries and in the chromate industry in the 1930s (8). In spite of the time that has since elapsed, situations remain, such as nickel exposure in the welding profession, in which it has not been possible to detect such a risk on account of the paucity of systematic investigations, even though the occurrence of the metal in question in low but measureable quantities would indicate a possibility of a risk.

The present study points to an increased cancer risk for arc welders of high alloy chromium-nickel steel. The cancer mortality was increased in the in- ternal comparison with turners, as well as in the external comparison with the general male population. As far as the risk of individual cancer sites is concerned, nothing definite can be stated at present. Among tumors of "other respiratory organs" two cases of mesothelioma among the welders were unusual findings (since these mesenchymal tumors are typically related to exposure to asbestos), and they have prompted further investigation. In one of the two cases a former occupational exposure to asbestos could be confirmed. In addition the welders were known to use asbestos-containing textile material for protection.

A separate analysis of the two most frequent welding processes showed that the increased risk of cancer with chromium-nickel welding was primarily caused by an increase of risk for welders who had welded with coated electrodes. In this connection, Sjögren (26) has reported that the smoke from coated electrodes has a stronger mutagenous effect in the Ames test than that originating in welding with shielding gas. Since one possible assumption is that the increased risks observed in our investigation are at least partly ascribable to chromium exposure, we refer to the categorization of metals according to the relative carcinogenic potency reported by Flessel et al (9). Although these evaluations were based on biological-experimental criteria, it seems remarkable that chromium and nickel (together with cadmium) are listed foremost in the group "most carcinogenic in humans." This potential may be reflected in the fact that welders emerged as a risk population for cancer but not for other causes of death in a study determining mortality in an industrial population whose exposure included combustion and pyrolytic products of welding (21). Due to the ubiquitous mixed exposure to nickel and chromium, no definite answer can be given to the question of a specific cancer risk due to nickel exposure in the present investigation.

Zober (28) reviewed the results of epidemiologic studies of welders (who were not chosen according to nickel exposure). Several studies showed lung cancer rates that lay significantly above the expected values. In most studies, consistently more deaths from lung cancer were observed than expected, although the increase was not statistically confirmed. We would like to emphasize, however, that the expected values applied in the comparison naturally depend on the respective reference population so that risk rates (and their formal statistical evaluation) are correspondingly sensitive. Since an appreciation of the risk is only possible if findings consistently point in the same direction, any additional study confirming these findings must be considered as corroborating evidence. Generally speaking, attention must be paid to the fact that "negative" cohort studies are possibly published more rarely and that case-referent studies appear more frequently in which welding is merely 
mentioned as one of the many risk factors investigated without a significant level being established.

In one large-scale analysis the proportional mortality rate from lung cancer (trachea and bronchus) among welders in the state of Washington in the United States (US) (1950-1971) showed a significant increase of 1.37 in the ratio of observed to expected deaths on the basis of the total US population (confidence limits 1.2-1.7) (17). However, the known weaknesses of the analysis of such proportional rates must be pointed out. A cross-sectional study of mortality and morbidity among 15400 welders in Los Angeles county (16), also in the US, yielded an increased rate of 1.37 (confidence limits $1.03-1.76$ ). In this investigation, as in every cross-sectional study, there was a danger of incomplete ascertainment due to the possibility of "survivors" being overrepresented. Two genuine cohort studies with rather large study populations of 3200 (again in Washington State) (2) and 128000 welders (in England) (20) found increased risk estimates for lung cancer, but did not yield any values exceeding 2.0. In a cohort of 243 stainless steel welders investigated in Sweden (26), there were three deaths from lung cancer where less than one death $(0.68)$ was expected on the basis of the total population. After adjustment for smoking habits, the risk rate remained unchanged at 4.4. It should be noted that the study was specifically designed for the determination of the cancer risk of chromium-exposed welders for whom the cumulative exposure to hexavalent chromium was given to be $3.4 \mathrm{mg} / \mathrm{m}^{3}$ per year. Polednak (23) followed a welders' cohort of 1059 persons exposed to nickel oxides for over 30 years (1943-1973) and found a standardized mortality ratio for lung cancer of 150 (87-240). In this case, too, the (age-adjusted) lung cancer risk increased with exposure time. Due to the fact that the study groups were too small, the results could not be statistically confirmed. Nevertheless they point in the same direction as the results of the present study. Polednak concluded that an increased risk of tumors of the respiratory system following nickel exposure cannot be excluded.

A case-referent study (4) among 493 US lung cancer cases in which smoking habits were accounted for yielded a relative risk of 1.5 for the occupational group of welders with a lower confidence limit of 1.1.

The fact that an overall increased cancer risk has been observed for chromium-nickel welding and that a contribution of nickel as a risk factor cannot be excluded in spite of a partial explanation by chromium exposure renders a directed investigation of pure nickel exposure desirable.

The strong interest in elucidating the question of a cancer risk among welders is also reflected by the fact that, besides several completed occupational studies $(2,5,6,7,10,13,18,22,23,24,26,27)$, other investigations are under way (19) concerning shipyard workers with correspondingly high cohort figures
(Finland, England), as well as concerning arc welders exposed to nickel and chromium fumes (US) but not exposed to asbestos, as can be expected in shipyards. In the meantime, a protocol has been worked out by the World Health Organization (Regional Office for Europe) which is recommended as a basis for planning future prospective studies.

\section{Acknowledgments}

We are indebted to the Arbeitsgemeinschaft der Eisenund Metall-Berufsgenossenschaften for their practical and financial support, which made this study possible. Without the enduring assistance and professional experience of I Grothe, MSc (Eng), and $\mathrm{H}$ Hölsken, MSc (Eng), this study would not have been feasible, and we want to thank them for their active support. We also thank $U$ Eilber for her invaluable help during the data collection, follow-up and data processing, and $\mathrm{U}$ Klappauf and $\mathrm{C}$ Apfel, who assisted in these tasks. The willing cooperation of many general practitioners and clinicians is highly appreciated, and the steady assistance in coding the causes of death by the Statistical Office of RhinelandPalatinate in Bad Ems is gratefully acknowledged.

\section{References}

1. Armstrong B. Epidemiologic identification of occupational carcinogens. Cancer Detect Prev 4 (1981) 1-7.

2. Beaumont JJ, Weiss DS. Lung cancer among welders. J Occup Med 23 (1981) 839-844.

3. Becker N, Stenger HJ. EPAS - Ein Programmpaket zur Auswertung epidemiologischer Studien. Deutsches Krebsforschungszentrum, Abteilung Epidemiologie, Heidelberg 1980. (Technical Report Nr 2).

4. Breslow L, Hoaglin G, Rasmussen H, Abrams K. Occupation and cigarette smoking as factors in lung cancer. Am J Public Health 44 (1954) 171-181.

5. Doll R. Cancer of the lung and nose in nickel workers. Br J Ind Med 15 (1958) 217-223.

6. Doll R, Mathews JD, Morgan LG. Cancers of the lung and nasal sinuses in nickel workers: $A$ reassessment of the period of risk. Br J Ind Med 34 (1977) 102-105.

7. Doll R, Morgan LG, Speitzer FE. Cancers of the lung and nasal sinuses in nickel workers. $\mathrm{Br} \mathrm{J}$ Cancer 24 (1970) 623-632.

8. Dunn HE, Weir JM. A prospective study of mortality of several occupational groups: Special emphasis on lung cancer. Arch Environ Health 17 (1968) 71-76.

9. Flessel CP, Furst A, Radding SB. A comparison of carcinogenic metals. In: Sigel H, ed. Metal ions in biological systems. Volume 10 (Carcinogenicity and metal ions). Marcel Dekker, Inc, New York, Basel 1980, pp 23-54.

10. Graham Jones J, Warner CG. Chronic exposure to iron oxide, chromium oxide, and nickel oxide fumes of metal dressers in a steelworks. Br J Ind Med 29 (1972) $169-177$.

11. Hueper WC. Some comments on the history and experimental explorations of metal carcinogens and cancers. J Natl Cancer Inst 62 (1979) 723-725.

12. International Agency for Research on Cancer. Cad- 
mium, nickel, some epoxides, miscellaneous industrial chemicals, and general considerations on volatile anaesthetics. Lyon 1976. (IARC monographs on the evaluation of carcinogenic risk of chemicals to man, volume 11).

13. Kreyberg L. Lung cancer in workers in a nickel refinery. Br J Ind Med 35 (1978) 109-116.

14. Langård S. Chromium. In: Waldron HA, ed. Metals in the environment. Academic press, London 1980, pp $111-133$.

15. Mastromatteo E. Nickel: A review of its occupational health aspects. J Occup Med 9 (1967) 127-136.

16. Menck HR, Henderson BE. Occupational differences in rates of lung cancer. J Occup Med 18 (1976) 797-801.

17. Milham S Jr. Cancer mortality patterns associated with exposure to metals. Ann NY Acad Sci 271 (1976) $243-249$.

18. Morgan JG. Some observations on the incidence of respiratory cancer in nickel workers. Br J Ind Med 15 (1958) 224-234.

19. Muir CS, Wagner G, ed. Directory of on-going research in cancer epidemiology 1983. International Agency for Research on Cancer, Lyon 1983 (IARC publications no 50).

20. Office of Populations Censuses and Surveys. Occupational mortality 1970-1972 England and Wales. Her Majesty's Stationery Office, London 1978.

21. Ott MG, Holder BB, Langner RR. Determinants of mortality in an industrial population. J Occup Med 18 (1976) $171-177$.

22. Pedersen E, Høgetveit AC, Andersen A. Cancer of respiratory organs among workers at a nickel refinery in
Norway. Int J Cancer 12 (1973) 32-41.

23. Polednak AP. Mortality among welders, including a group exposed to nickel oxides. Arch Environ Health 36 (1981) 235-242.

24. Puntoni R, Vercelli M, Merlo F, Valerio F, Santi L. Mortality among shipyard workers in Genoa, Italy. Ann NY Acad Sci 330 (1979) 353-377.

25. Rothman KJ, Boice JD Jr. Epidemiologic analysis with a programmable calculator. US Government Printing Office, Washington, DC 1979. (NIH pub no 79-1649).

26. Sjögren B. A retrospective cohort study of mortality among stainless steel welders. Scand J Work Environ Health 6 (1980) 197-200.

27. Stern RM. Process dependent risk of delayed health effects for welders. Environ Health Perspect 41 (1981) $235-253$

28. Zober MA. Arbeitsmedizinische Untersuchungen zur inhalativen Belastung von Lichtbogen-Schmelzschweißern. Habilitationsschrift der Medizinischen Fakultät der Friedrich-Alexander-Universität ErlangenNürnberg. Ed.: Bundesanstalt für Arbeitsschutz und Unfallforschung, Dortmund 1982. (Forschungsbericht 317).

29. Zober MA, Weltle D, Schaller KH. Study of the kinetics of chromium and nickel in biological material during a week of arc welding work using chrom-nickelcontaining filler metals. Schweißen und Schneiden, intl ed. (in press).

Received for publication: 6 August 1984 